\title{
To kill a tumor cell: the potential of proapoptotic receptor agonists
}

\author{
Avi Ashkenazi ${ }^{1}$ and Roy S. Herbst ${ }^{2}$ \\ ${ }^{1}$ Genentech, South San Francisco, California, USA. ${ }^{2}$ Departments of Thoracic/Head and Neck Medical Oncology and Cancer Biology, \\ The University of Texas MD Anderson Cancer Center, Houston, Texas, USA.
}

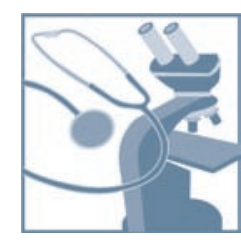

Disturbances in mechanisms that direct abnormal cells to undergo apoptosis frequently and critically contribute to tumorigenesis, yielding a logical target for potential therapeutic intervention. There is currently heightened interest in the extrinsic apoptosis pathway, with several proapoptotic receptor agonists (PARAs) in development. The PARAs include the ligand recombinant human Apo2L/TRAIL and agonistic mAbs. Mechanistic and preclinical data with Apo2L/TRAIL indicate exciting opportunities for synergy with conventional therapies and for combining PARAs with other molecularly targeted agents. Novel molecular biomarkers may help identify those patients most likely to benefit from PARA therapy.

\section{What is apoptosis?}

Apoptosis is one of several mechanisms leading to cell death. Apoptosis is a built-in cell suicide program that serves to eliminate cells in the organism that are no longer needed or have sustained severe damage, e.g., to their DNA or cytoskeleton (1). Historically, the term apoptosis often has been used synonymously with programmed cell death. More recently, other mechanisms of programmed cell death have been identified, including autophagy, paraptosis, and mitotic catastrophe (2). Accordingly, apoptosis may now be more accurately referred to as a mechanism of cell death mediated principally by caspases (a specialized family of aspartate-specific cysteine proteases that carry out this form of cellular suicide).

Apoptotic stimuli include developmental cues, the activation of specific proapoptotic receptors, and cellular stress or injury caused by loss of growth factor signals, heat shock, irradiation, cytotoxic drugs, bacteria, and viruses (3). Apoptosis occurs principally via two separate yet interlinked signaling mechanisms: the extrinsic pathway, activated by proapoptotic receptor signals at the cellular surface, and the intrinsic pathway, activated by mitochondrial signals from within the cell (Figure 1). These pathways converge through "effector" caspases, which orchestrate the apoptotic program (4).

\section{The caspase cascade}

The caspase cascade acts as the principal executioner in apoptosis (4-6). Caspases are synthesized as inactive zymogens (procaspases), which require proteolytic processing to become fully active. The caspases are categorized as either proinflammatory (caspases 1, $4,5,11,12,13$, and 14 ) or proapoptotic. The latter can be further grouped as initiators (caspases 2, 8, 9, and 10) and effectors

Nonstandard abbreviations used: Apaf-1, apoptotic protease-activating factor 1; Apo2L/TRAIL, Apo2 ligand/TNF-related apoptosis-inducing ligand; BH3, Bcl-2 homology 3; CRC, colorectal cancer; DISC, death-inducing signaling complex; DLT, dose-limiting toxicity; IAP, inhibitor of apoptosis; MTD, maximum tolerated dose; NHL, non-Hodgkin lymphoma; NSCLC, non-small cell lung cancer; PARA, proapoptotic receptor agonist; PR, partial response; rhApo2L/TRAIL, recombinant human Apo2L/TRAIL; SAE, serious adverse event; SD, stable disease.

Conflict of interest: Avi Ashkenazi is a full-time employee of Genentech and owns stock in the company. Roy S. Herbst has received research funding from Genentech and Amgen.

Citation for this article: J. Clin. Invest. 118:1979-1990 (2008). doi:10.1172/JCI34359. (caspases 3, 6, and 7). Once switched on, the initiators activate the effectors, which then execute apoptosis (Figure 1) (4).

The caspases are modulated by several cell-endogenous factors, including inhibitor of apoptosis (IAP) proteins such as XIAP and ML-IAP, which inhibit caspases 3, 7, and 9, and cellular FLIP (c-FLIP), which inhibits procaspases 8 and 10 (7). Certain viruses also encode caspase inhibitory proteins, e.g., v-FLIP (8) and Crm-A, which inhibit caspase 8 , or the pancaspase inhibitor p35 $(4,5)$.

\section{The intrinsic apoptosis pathway}

The intrinsic pathway is triggered by loss of growth factor signals in embryonic tissues or by severe cell stress (e.g., DNA damage) in adult tissues (9-11). This pathway is controlled by interactions between pro- and antiapoptotic members of the Bcl-2 protein family. Specific proapoptotic family members can cause permeabilization of the mitochondrial outer membrane and hence the release of soluble molecules such as cytochrome $c$ and Smac/DIABLO into the cytoplasm. Cytochrome $c$ stimulates apoptosome formation (a complex comprising apoptotic protease-activating factor 1 [Apaf-1], dATP, cytochrome $c$, and caspase 9), followed by activation of caspase 9, which in turn cleaves downstream effector caspases 3, 6, and 7; Smac/DIABLO binds to IAPs and reverses their inhibitory interactions with caspases (12) (Figure 1). One arm of the Bcl-2 family (including Bcl-2, Bcl- $\mathrm{X}_{\mathrm{L}}, \mathrm{Mcl}-1, \mathrm{Bcl}-\mathrm{W}, \mathrm{Bfl}-1$, and $\mathrm{Bcl}-\mathrm{B}$ ) promotes cell survival, whereas two additional subgroups (one including Bax, Bak, and Bok and the other consisting of so-called Bcl-2 homology 3-only [BH3-only] proteins such as Bid, Bim, Bad, Puma, Noxa, and others) drives apoptosis $(9-11,13)$. Specific apoptosis stimuli activate certain $\mathrm{BH}$-only proteins by transcriptional induction or posttranscriptional changes to disrupt the equilibrium between antiapoptotic and proapoptotic Bcl-2 family proteins. This occurs mainly through binding of BH3-only proteins to cognate antiapoptotic $\mathrm{Bcl}-2$ proteins, preventing their inhibitory interaction with proapoptotic counterparts (14).

The tumor-suppressor p53 protein is a critical checkpoint for activation of the intrinsic pathway: p53 responds to diverse cellular stresses by arresting cell-cycle progression through expression of p53 target genes such as p21. In the context of extensive damage that the cell cannot repair, $\mathrm{p} 53$ promotes apoptosis via the expression of other genes (e.g., puma, noxa, bax, apaf-1, fas, and DR5) (15) 


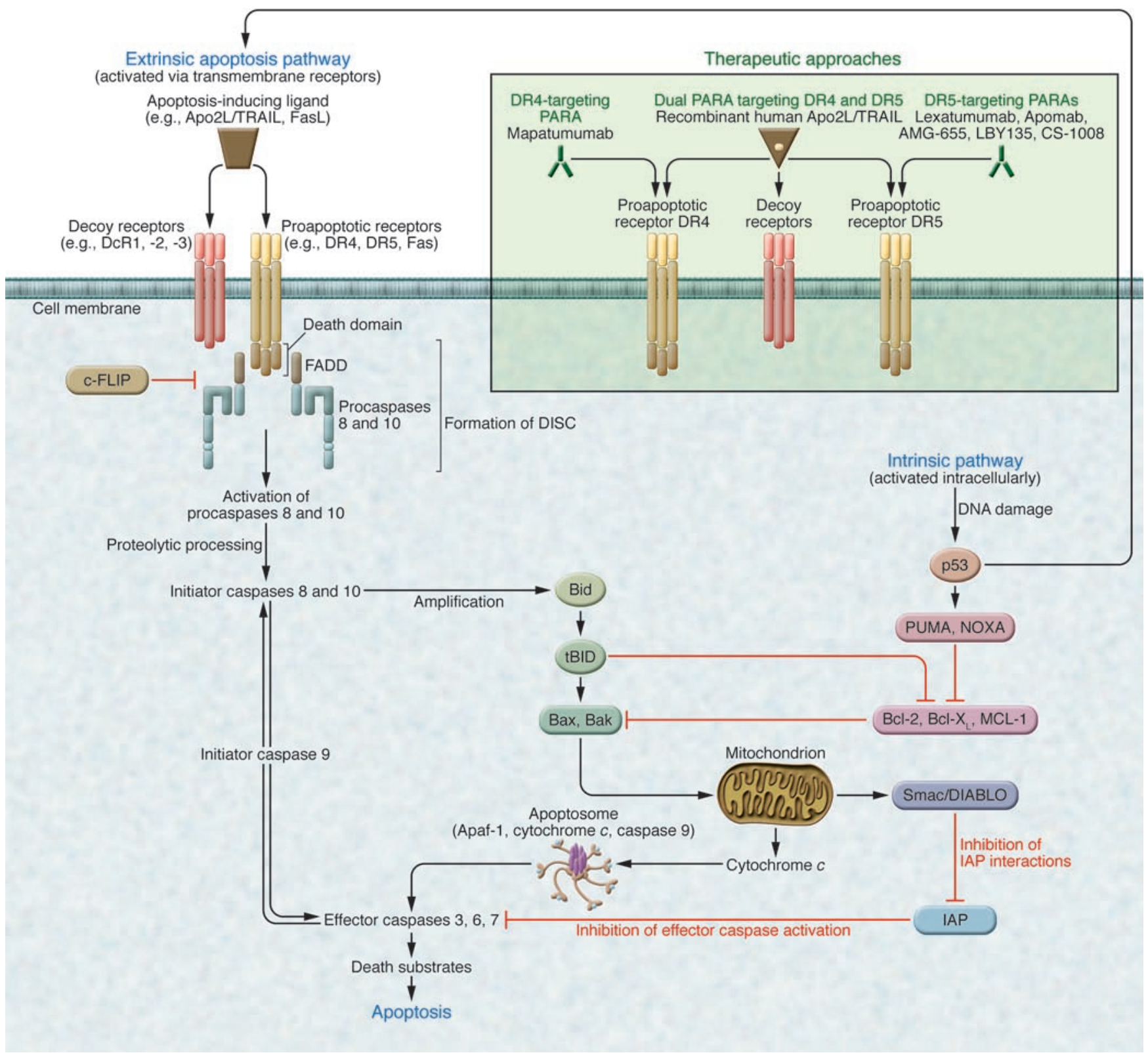

Figure 1

Extrinsic and intrinsic apoptosis pathways and caspase modulation (see text for further detail). Therapeutic approaches to proapoptotic receptor activation are illustrated in the green insert. FADD, Fas-associated death domain.

or by inhibiting the expression of key antiapoptotic proteins (e.g., Bcl-2 and Bcl- $\left.\mathrm{X}_{\mathrm{L}}\right)(16)$.

\section{The extrinsic apoptosis pathway}

Extrinsic apoptosis signals are initiated through the activation of specialized proapoptotic membrane receptors (a subgroup of the TNF receptor superfamily) by ligands such as FasL (also known as CD95L) (receptor Fas [or CD95]) and Apo2 ligand/TNF-related apoptosis-inducing ligand (Apo2L/TRAIL) (receptors DR4 and DR5) $(9,17,18)$. Once activated, these receptors recruit the adapter molecule Fas-associated death domain, the binding of which promotes the recruitment of initiator procaspases 8 and 10 . The resulting protein assembly comprises the death-inducing signaling complex (DISC) (Figure 1).

Two types of intracellular signaling have been established for the extrinsic apoptosis pathway, characterized by generation of high (type I) or low (type II) levels of DISC and caspase 8 activity upon receptor stimulation $(4,19,20)$. Caspase 8 stimulation in type I cells is sufficient to activate effector caspases and commit the cell to apoptotic death. In type II cells, further amplification of the signal is needed for apoptosis activation. This occurs through caspase 8-dependent cleavage of the $\mathrm{BH} 3$-only protein Bid, which then engages the intrinsic pathway to produce greater effector caspase activity $(21,22)$. Type II signaling might be blocked by overex- 
Table 1

Development status of PARAs targeting DR4 and/or DR5

Agent/identifier
rhAp02L/TRAIL (PR01762, AMG-951)
Mapatumumab (HGS-ETR1)
Lexatumumab (HGS-ETR2)
Apomab
AMG-655
LBY135
TRA-8/CS-1008
Ad5-TRAIL

Ad5-TRAIL

\author{
Mechanism/pharmacology \\ rhApo2L/TRAIL targeting DR4 and DR5 \\ Human mAb targeting DR4 \\ Human mAb targeting DR5 \\ Human mAb targeting DR5 \\ Human mAb targeting DR5 \\ Chimeric mAb targeting DR5
}

Murine DR5-targeting antibody (TRA-8) and humanized version CS-1008

Recombinant adenovirus encoding human Apo2L/TRAIL

\author{
Development stage \\ Phase II (NHL, NSCLC) \\ Phase II (NHL, CRC, NSCLC, MM) \\ Phase I \\ Phase II (NHL, NSCLC) \\ Phase II (NSCLC) \\ Phase I/II \\ Phase I \\ Phase I
}

MM, multiple myeloma.

pression of antiapoptotic $\mathrm{Bcl}-2$ proteins such as $\mathrm{Bcl}-2$ and $\mathrm{Bcl}-\mathrm{X}_{\mathrm{L}}$ or - in DNA mismatch repair-deficient tumors - by mutational inactivation of Bax, although this may be limited to cells with low baseline levels of Bak $(23,24)$.

Studies of the physiological role of Apo2L/TRAIL suggest that this ligand plays a role in immune surveillance and the regulation of adaptive immune responses via the $\mathrm{CD}^{+} \mathrm{T}$ cell-dependent generation of $\mathrm{CD}^{+}$memory $\mathrm{T}$ cells $(25,26)$. Moreover, it mediates part of the antitumor and antiviral cytotoxicity of dendritic cells, monocytes, NK cells, and T cells (27). There is also some evidence that some of the antitumor and antiviral effects of IFNs are mediated by Apo2L/TRAIL (28-30).

\section{How is apoptosis targeted?}

The rationale for targeting apoptosis in the treatment of cancer is based on the observation that this process is deregulated in cancer cells but not normal cells $(1,17,31-33)$. Cancer cells have acquired blocks to apoptosis but are nevertheless constantly driven to initiate it by genomic and other aberrations. Thus, if proapoptotic pathways could be stimulated, these cells would be more susceptible to death than normal cells.

The promotion of apoptosis is an important component of the antitumor activity of traditional anticancer therapies, including chemotherapeutic drugs and radiotherapy $(33,34)$. Conventional anticancer therapies appear to stimulate apoptosis primarily via the intrinsic pathway, and impairment of apoptosis may contribute to the resistance of cancer cells to such therapy (33-35). Inactivation of $\mathrm{p} 53$ is among the most common mutations, occurring in over half of cancers, and provides a key resistance mechanism that helps cancer cells to avoid apoptosis induction in response to several types of damage caused by conventional therapy (36-38).

Because the extrinsic pathway triggers apoptosis independently of p53, therapies that directly activate this mechanism have the potential to induce cell death in cancers with a wide spectrum of responsiveness to conventional therapies (37). Notwithstanding the issue of drug resistance, conventional anticancer therapies often are limited by systemic toxicities. Thus, there is a need for safer and more effective agents that target cancer cells more selectively and circumvent treatment resistance. The promotion of apoptosis is emerging as a key strategy to treat cancer (13, 39-41), and considerable effort has been invested in identifying proapoptotic targets with therapeutic potential.

Several strategies involving the extrinsic and/or intrinsic pathways have emerged as the main focus of research $(40,41)$. These include targeted activation of the extrinsic pathway through pro- apoptotic receptors, inhibition of Bcl-2 family of proteins, caspase modulation, and IAP inhibition.

\section{The extrinsic pathway: proapoptotic receptors as therapeutic targets}

The main function of TNF- $\alpha$ is to stimulate proinflammatory gene expression through TNFR1-mediated activation of the transcription factor NF-кB. However, this ligand can stimulate apoptosis under special circumstances through its death domain-containing receptor TNFR1, for example, when NF- $\kappa \mathrm{B}$ activation is blocked. TNF- $\alpha$ has shown significant efficacy in the treatment of soft tissue sarcoma of the extremities following isolated limb perfusion (42), possibly through its effects on endothelial cells within tumor vasculature.

The proapoptotic ligand FasL has potent cytotoxic activity against various types of tumor cells; however, hepatotoxic side effects limit the use of Fas-targeted therapy (43). In contrast, stimulation of the proapoptotic receptors DR4 and DR5 by optimized soluble recombinant human Apo2L/TRAIL (rhApo2L/TRAIL is being jointly developed by Genentech and Amgen) or by DR4- or DR5-selective mAbs may represent a more appropriate approach, delivering potent antitumor activity but minimal cytotoxicity in normal cells (44-47). Although expression of DR4 and DR5 is detectable in several tissues, there is evidence suggesting that it is generally lower in normal healthy cells than in cancer cells (48).

Furthermore, some tumor cells that are resistant to apoptosis induction by FasL are sensitive to Apo2L/TRAIL, including follicular epithelial thyroid carcinomas (49), pediatric rhabdomyosarcoma cells (50), and melanoma cells (51).

The intriguing capacity of the proapoptotic ligand Apo2L/ TRAIL to trigger apoptosis selectively in cancer cells while sparing normal cells has motivated extensive research efforts. The results of preclinical studies demonstrating the ability of Apo2L/TRAIL to act synergistically with conventional anticancer therapies in a broad range of solid and hematologic malignancies are particularly compelling $(44,52-58)$. This cooperation may be attributed to the supplementary activation of the caspase cascade via both the extrinsic and intrinsic pathways $(37,53,54)$. An additional contributing mechanism may involve the upregulation of DR5 transcription by p53 (59). Furthermore, Apo2L/TRAIL has been shown in certain models to overcome cancer cell resistance to chemotherapy (60) and to cooperate with chemotherapy even in p53-deficient cells (61). In accordance with these observations, several proapoptotic receptor agonists (PARAs) are in clinical development (Table 1). 
Table 2

Effect of the addition of "sensitizing" agents to Apo2L/TRAIL in preclinical cell and animal models

\section{Tumor type Cell line(s) \\ Conventional chemotherapy \\ Colon HCT116, COL0201, COLO205}

HT29, SW620, COL0205, HCT15

HT29, HCT116, SW480, HCT8R Surgical specimens engrafted onto SCID mice HCT116

HCT116

Prostate

PC3

PC3, DU145, LNCaP

C42

\begin{tabular}{|c|c|}
\hline Pancreatic & $\begin{array}{l}\text { Surgical specimens } \\
\text { engrafted onto SCID mice }\end{array}$ \\
\hline Renal/bladder & $\begin{array}{l}\text { T24, J82, HT1197 } \\
\text { (bladder) + } 3 \text { surgical } \\
\text { specimens }\end{array}$ \\
\hline Ovarian & $\begin{array}{l}\text { A2780, SKOV3 } \\
12 \text { chemoresistant } \\
\text { cell lines }\end{array}$ \\
\hline NSCLC & $\begin{array}{l}\text { A549, NCI-H358, Calu1, } \\
\text { Calu6, SkMes1, SkLu1 }\end{array}$ \\
\hline & $\begin{array}{l}\mathrm{NCl}-\mathrm{H} 460 \text {-based } \\
\text { xenograft models }\end{array}$ \\
\hline
\end{tabular}

Various cell lines

\section{Proteasome inhibitors}

$\begin{array}{cl}\text { Colon } & \text { COLO205, HCT15, } \\ & \text { KM12, SW620 } \\ \text { HCT116, HC4 }\end{array}$

DLD1-TRAIL/R, LOVO-TRAIL/R

Breast HS578T, MDA-MB-435, BT549, MDA-MB-231, MCF7, T47D

Renal/bladder A498, ACHN, CAK1, SN12C, TK10, U031, 786-0 (renal)

\section{Agents}

CAM or $5-\mathrm{FU}+$ rhApo2L/TRAIL

CAM + rhApo2L/TRAIL

CIS or DOX + Apo2L/TRAIL

CAM or 5-FU + rhApo2L/TRAIL

IRI + rhApo2L/TRAIL

CAM + rhApo2L/TRAIL

DOX + Apo2L/TRAIL

PAC + Apo2L/TRAIL

CAM + rhApo2L/TRAIL

GEM + rhApo2L/TRAIL

DOX + rhApo2L/TRAIL

PAC or CIS + Ap02L/TRAIL

CIS, DOX, or PAC + Apo2L/TRAIL

CIS, PAC, DOX, 5-FU, $\mathrm{CAM}+\mathrm{Ap02L} / \mathrm{TRAIL}$

PAC + CAR + rhApo2L/TRAIL

PAC + Apo2L/TRAIL, FasL or anti-DR5 antibody

BOR + rhApo2L/TRAIL

$\mathrm{BOR}+\mathrm{Ap02L/TRAIL}$

BOR or MG132 + Ap02L/TRAIL

BOR + rhApo2L/TRAIL

BOR + rhApo2L/TRAIL
Key synergistic effects

Reference

Synergism between rhApo2L/TRAIL and chemotherapy yielded tumor regression or complete tumor ablation in mouse xenografts rhApo2L/TRAIL-resistant HT29 and SW620 cells rendered sensitive; sensitivity increased in COLO205 and HCT15 cells

Increased cellular toxicity of Apo2L/TRAIL with addition of CIS or DOX

Greatly enhanced antitumor effect ( $50 \%$ complete tumor regression with CAM + rhApo2L/TRAIL)

Increased apoptosis (via p53-independent mechanism)

DR4 and DR5 upregulation; caspase-dependent degradation of $\mathrm{p} 21$, reversal of G2/M-phase arrest, and increased apoptosis

Increased apoptosis and decreased tumor growth with addition of DOX; PC3 cells partially sensitive to Apo2L/TRAIL

Increased apoptosis with sequential PAC and then Apo2L/TRAIL versus Apo2L/TRAIL alone (increased processing of procaspase 8 , Bid, and caspase 3 )

Upregulation and activation of $B a x$ and $B c l-X_{L}$ in vitro; induction of $\mathrm{Bax}$ and $\mathrm{Bcl}-\mathrm{X}_{\mathrm{S}}$ with $\mathrm{BCl}-\omega$ and $\mathrm{Bcl}-\mathrm{X}_{\mathrm{L}}$ downregulation in xenografts. Caspase 8 and Bid activation Increased growth inhibition (including in tumors resistant to GEM or Apo2L/TRAIL alone)

Synergism in all cells tested. T24 cells (resistant to Apo2L/TRAIL) also sensitive to combination treatment with rhApo2L/TRAIL + epirubicin or pirarubicin

Increased activity of PAC and CIS in both Apo2L/

TRAIL-insensitive cell lines

Significant synergistic growth inhibition over a wide range of concentrations

Significant increase in the rate of Apo2L/TRAIL-induced apoptosis; no correlation between the level of sensitization and c-FLIP

Tumor regression and substantial growth delay with combination therapy versus partial regression with chemotherapy or rhApo2L/TRAIL alone; significant improvement in 90-day survival; cooperation against subcutaneous and lung orthotopic tumor xenografts Significant enhancement of apoptotic effect in multiple cell lines

Sensitization of KM12 and SW620 cell lines but not COL0205 or HCT15

Increased apoptosis in Bax-negative Apo2L/TRAILresistant HC4 cells; lowered threshold for HCT116 cell killing

Increased apoptosis induction with both proteasome inhibitors (enhanced cleavage of caspases 8, 9, and 3 and Bid, and release of cytochrome $c$ and Smac/DIABLO) Significant sensitization of HS578T and MDA-MB-435; weak sensitization of BT549 and MDA-MB-231; MCF7 and T47D resistant to sensitization

A498 and ACHN very effectively sensitized; TK10 and U031 moderately sensitized; CAK1, 786-0, and SN12C not sensitized 


$\begin{array}{ll}\begin{array}{l}\text { Tumor type Cell line(s) } \\ \text { Bcl-2 inhibitors } \\ \text { Prostate }\end{array} & \text { C42 } \\ \begin{array}{l}\text { IAP antagonists } \\ \text { Leukemia }\end{array} & \text { Jurkat } \\ \text { Glioblastoma } & \text { T98G } \\ \text { Neuroblastoma } & \text { SHEP } \\ & \text { SHEP/Bcl-2, SH-SY5Y } \\ \text { Melanoma } & \text { Mel-H0 } \\ \text { Pancreas } & \text { Panc1 } \\ \text { Glioma } & \text { Human U87MG xenograft }\end{array}$

\begin{tabular}{|c|c|}
\hline $\begin{array}{l}\text { Leukemia/ } \\
\text { lymphoma }\end{array}$ & Jurkat, HL60 \\
\hline \multicolumn{2}{|l|}{ CD20 antibody } \\
\hline $\begin{array}{l}\text { Leukemia/ } \\
\text { lymphoma }\end{array}$ & $\begin{array}{l}\text { NHL lines BJAB, } \\
\text { Ramos RA1, DoHH2 }\end{array}$ \\
\hline \multicolumn{2}{|l|}{ Irradiation } \\
\hline Prostate & PC3 (in mice) \\
\hline Breast & Xenografts in nude mice \\
\hline \multicolumn{2}{|c|}{ Synthetic triterpenoids } \\
\hline Breast & T47D, MDA-MB-468 \\
\hline
\end{tabular}

\section{HDAC inhibitors}

Agents

BH3I-2' (Bcl-X $\mathrm{X}_{\mathrm{L}}$ inhibitor) + rhApo2L/TRAIL

Smac-7 or Smac-4 (Smac mimetics) + Apo2L/TRAIL

Small molecule Smac mimetic + Apo2L/TRAIL

Synthetic Smac peptides + Apo2L/TRAIL

Synthetic Smac peptides + Apo2L/TRAIL

Synthetic Smac peptides + Apo2L/TRAIL

Synthetic Smac peptides + Apo2L/TRAIL

Synthetic Smac peptides + Apo2L/TRAIL

$\mathrm{HDACl}+$ Apo2L/TRAIL

Rituximab + rhApo2L/TRAIL

Irradiation + rhApo2L/TRAIL

Irradiation + rhApo2L/TRAIL

Synthetic triterpenoids + Apo2L/TRAIL

Sorafenib + Apo2L/TRAIL

Sorafenib + Apo2L/TRAIL

Sorafenib + Apo2L/TRAIL

Sorafenib + Apo2L/TRAIL

Sorafenib + Apo2L/TRAIL U937, K562, myelogenous leukemia blasts

Lymphoma Raji, Jurkat, Karpas Myeloma U266
Key synergistic effects

Reference

Synergistic induction of apoptosis via activation of caspase 8 and Bid (leading to activation of caspase 3 )

Significant increase in apoptosis via activation of 89 caspase 3 and downregulation of XIAP, CIAP1 and survivin Caspase 8 and caspase 3 activation and extensive apoptosis

Marked enhancement of apoptosis

91

Sensitization to Apo2L/TRAIL-induced apoptosis

91

Sensitization to Apo2L/TRAIL-induced apoptosis

91

Sensitization to Apo2L/TRAIL-induced apoptosis

91

Sensitization to Apo2L/TRAIL-induced apoptosis, complete eradication of established tumors, and improved survival

Strong induction of apoptosis in cells resistant to Apo2L/TRAIL alone, but not in normal PBMCs

2- to 3-fold increase in cytotoxicity of rhApo2L/TRAIL in vitro and substantial and prolonged tumor regression in xenografted SCID mice with combination therapy

Synergism characterized by upregulation of DR5, Bax, and Bak

Augmentation of apoptosis through upregulation of DR5

Conversion of Apo2L/TRAIL-resistant T47D and MDA-MB-468 cells to Apo2L/TRAIL-sensitive and increased frequency of apoptosis compared with either monotherapy; reduced tumor burden in vivo (MDA-MB-468 tumor xenograft model)

Sensitization to Apo2L/TRAIL-induced apoptosis, reduced 70 levels of TRAIL-induced Mcl-1 and cIAP2 in bax ${ }^{-1-}$ cells

Significant inhibition of continued tumor growth in HCT116 model and almost complete disappearance of tumor cell mass in HT29 model

Sensitization to Apo2L/TRAIL-induced apoptosis $\quad 70$

Synergistic increase in apoptosis, increased Bak activation in Jurkat cells

Synergistic increase in apoptosis, downregulation of $\mathrm{Bcl}-\mathrm{X}_{\mathrm{L}}$, reduced $\mathrm{Mcl}-1$ expression, increased Bid activation, conformational changes in Bak and Bax and Bax translocation in U937 cells

Synergistic increase in apoptosis Synergistic increase in apoptosis

BOR, bortezomib (PS-341); CAM, camptothecin (CPT-11); CAR, carboplatin; CIS, cisplatin; CK2, casein kinase II; DOX, doxorubicin; 5-FU, 5-fluorouracil; GEM, gemcitabine; HDACI, histone deacetylase inhibitor; IRI, irinotecan; PAC, paclitaxel. 
DR4 and DR5 receptor levels do not generally show a direct correlation with sensitivity to apoptosis stimulation $(17,62)$. The elucidation of mechanisms underlying resistance and identification of biomarkers that may predict sensitivity are areas of active investigation (63). Resistance mechanisms that have been documented to date in specific cancer cell lines include regulation of proapoptotic receptor transport to the cell surface (64), Bcl-2-mediated inhibition of a mitochondrial amplification step (65), bax mutation (23), and bax or bak gene deficiency (66). The caspase 8-related protein c-FLIP can block caspase 8 activation by DR4 and DR5 (67) and may contribute to resistance in some instances.

Studies are now underway to identify and characterize potential biomarkers for sensitivity to Apo2L/TRAIL, with promising results already emerging. A strong correlation has been found recently between sensitivity to Apo2L/TRAIL and expression of specific O-glycosylation enzymes (68). A range of human cancer cells has been shown to overexpress such O-glycosyltransferases, and these enzymes may play a role in regulating apoptosis signaling through DR4 and DR5. The O-glycosylation initiating enzyme GALNT14 correlates significantly with Apo2L/TRAIL sensitivity in non-small cell lung cancer (NSCLC), pancreatic cancer, and melanoma cell lines, while initiating enzyme GALNT3 together with the O-glycan processing enzymes FUT3 and FUT6 correlates with sensitivity in colorectal cancer (CRC) cells. DR4 and DR5 possess conserved O-glycosylation sites that appear to promote ligand-induced receptor clustering, DISC assembly, and caspase 8 activation. Hence, specific O-glycosylation enzymes or their modified products may provide predictive biomarkers for responsiveness to PARA therapy.

Another promising approach involves the myc oncogene, which has been identified as a potential marker for Apo2L/TRAIL sensitivity in cancer cells, including those with defective intrinsic pathway signaling (69). Building on this finding, the potential for combining Apo2L/TRAIL with the kinase inhibitor sorafenib to target cancer cells harboring defective intrinsic apoptotic machinery has recently been demonstrated (70-72).

\section{Preclinical findings with Apo2L/TRAIL}

The combination of PARAs and numerous conventional and investigational anticancer agents has been tested in diverse preclinical models (44, 54, 55, 57, 58, 61, 70, 71-94) (Table 2).

Cytotoxic agents for which a synergistic effect has been reported include irinotecan, camptothecin, 5-fluorouracil, carboplatin, paclitaxel, doxorubicin, and gemcitabine. Potential mechanisms for these synergies and the cell lines or models in which they were observed are summarized in Table 2 .

Encouraging results also have been reported for the addition of various other anticancer agents that appear to sensitize tumor cells to the effects of Apo2L/TRAIL. Combination of the proteasome inhibitor bortezomib with Apo2L/TRAIL in cell lines generated from various solid tumors including those of the colon, breast, or kidney and bladder led to increased apoptosis induction (85-87). In a colon cancer model, the small molecule Bcl-2 inhibitor HA14-1 enhanced apoptotic signaling (65). Apo2L/TRAIL plus a $\mathrm{BH} 3$ mimetic $\mathrm{Bcl}-2$ inhibitor induced apoptosis synergistically in human prostate cancer cells through both the extrinsic and intrinsic pathways (88). Indeed, enhanced activation of caspase 8 and Bid has been observed with both this combination and camptothecin $(78,88)$. Furthermore, in Apo2L/TRAIL-resistant breast cancer cell lines, the addition of synthetic triterpenoids restored
Apo2L/TRAIL sensitivity in vitro and reduced tumor burden in a xenograft model in vivo (94).

Hematologic malignancies also are susceptible to Apo2L/ TRAIL-based combination therapy. Histone deacetylase inhibitors upregulated DR5 and synergistically sensitized cells to Apo2L/TRAIL-induced apoptosis in leukemia cell lines (92), while the anti-CD20 mAb rituximab cooperated with Apo2L/TRAIL to cause tumor regression in non-Hodgkin lymphoma (NHL) xenograft models (93).

Sensitization of tumor cells sometimes involves the BH3-only proteins Bik and Bim (95). However, Apo2L/TRAIL and Bim have a role as response modifiers of hepatocyte apoptosis; consequently, there is a need for ongoing investigation of the hepatic effect of triggering the proapoptotic receptors DR4 and DR5, particularly when stimulated in combination with other drugs (96). It is notable that human hepatocytes are sensitive to nonoptimized preparations of Apo2L/TRAIL but show little or no sensitivity to optimized rhApo2L/TRAIL (47) and other nontagged versions of the protein $(97,98)$. Because native Apo2L/TRAIL is a zinc-coordinated protein, one possibility is that insufficient amounts of zinc and/or added exogenous sequence tags in the nonoptimized preparations interfere with the protein's conformation, leading to decreased solubility. This promotes aggregation, which can augment activity toward normal cells by inducing excessive clustering of proapoptotic receptors $(47,97,98)$. In contrast, the optimized, nontagged rhApo2L/TRAIL protein contains near stoichiometric amounts of zinc and forms a stable, soluble trimer that does not display cytotoxicity toward hepatocytes (47).

An alternative approach to activating the proapoptotic receptors relies on agonistic antibodies $(17,99)$. Most recently, preclinical data have been reported for the agonistic mAb Apomab (100). In NSCLC and colon cancer cell lines, exposure to Apomab resulted in clustering of DR5 molecules on the cell surface and the stimulation of DISC formation followed by apoptosis. Apomab exerted antitumor activity as a single agent in xenograft models based on H2122 NSCLC cells, Colo205 colon carcinoma cells, and BxPC3 pancreatic ductal adenocarcinoma cells. Furthermore, Apomab cooperated with camptothecin or gemcitabine, respectively, against colon or pancreatic cancer xenografts. Crystallographic studies revealed that Apomab interacts with a DR5 region that overlaps the Apo2L/TRAIL-binding site, perhaps facilitating its agonistic activity.

Taken together, these preclinical data are encouraging with regard to the potential for effective combinatorial treatment modalities. Although preclinical data from rodent xenograft-based efficacy models and nonhuman primate safety models demonstrate apoptotic activity for these molecules, careful investigation in cancer patients is underway to confirm the therapeutic activity in a clinical setting. Comparative studies both at the preclinical and clinical level will be needed to determine which combinations offer the most effective modalities with the least toxicity.

\section{Clinical development of PARAs}

Of the PARAs in development, the DR4-targeting mAb mapatumumab is the subject of the most advanced studies, with phase II results available (Table 3). Phase I data also exist for the dual (DR4and DR5-targeting) PARA rhApo2L/TRAIL $(101,102)$ and DR5targeting mAbs lexatumumab, Apomab, and AMG-655 (Table 3).

Phase Ia studies indicate that mapatumumab is well tolerated, and the maximum tolerated dose (MTD) has yet to be 
Table 3

Completed clinical studies with PARAs

Treatment schedule
(study phase)
rhApo2L/TRAIL
rhApo2L/TRAIL 0.5, 1.5, 4.0, 8.0,
$15 \mathrm{mg} / \mathrm{kg} \mathrm{d} 1-5$ q3w for $\leq 8$ cycles
(phase la; interim data)
rhApo2L/TRAIL 4.0, $8.0 \mathrm{mg} / \mathrm{kg}$
d 1-5 q3w for 4 cycles + rituximab
$375 \mathrm{mg} / \mathrm{m}^{2}$ q1w ×8 (phase lb;
interim data)
Mapatumumab (HGS-ETR1)
Mapatumumab 0.01, 0.03,
$0.1 \mathrm{mg} / \mathrm{kg}$ q8w, $0.3 \mathrm{mg} / \mathrm{kg} \mathrm{q4/8w,}$
$1.0,3.0,10.0 \mathrm{mg} / \mathrm{kg} \mathrm{q4w,}$
$10.0 \mathrm{mg} / \mathrm{kg}$ q2w (phase la)

Mapatumumab 0.01, 0.03, 0.3, 3.0, $10.0,20.0 \mathrm{mg} / \mathrm{kg} \mathrm{q} 4 \mathrm{w}$ (phase la; interim data)

Mapatumumab 3.0, 10.0, 20.0

$\mathrm{mg} / \mathrm{kg}$ + paclitaxel $200 \mathrm{mg} / \mathrm{m}^{2}$ + carboplatin AUC 6 q3w for $\leq 6$ cycles (phase Ib)

Mapatumumab 1.0, 3.0, 10.0, 20.0, $30.0 \mathrm{mg} / \mathrm{kg} \mathrm{d} 1$ (d 2, cycle 1$)+$ gemcitabine $1250 \mathrm{mg} / \mathrm{m}^{2} \mathrm{~d} 1-8+$ cisplatin $80 \mathrm{mg} / \mathrm{m}^{2} \mathrm{~d} 1 \mathrm{q} 3 \mathrm{w}$ for $\leq 6$ cycles (phase lb; interim data)

Mapatumumab 3.0, $10.0 \mathrm{mg} / \mathrm{kg}$ q3w for $\leq 6$ cycles (phase II)

Mapatumumab $20.0 \mathrm{mg} / \mathrm{kg}$ q2w for 2 cycles followed by $10.0 \mathrm{mg} / \mathrm{kg}$ q2w for 4 cycles (phase II)

Mapatumumab $10.0 \mathrm{mg} / \mathrm{kg}$ q3w (phase II) for $\leq 4$ cycles (phase II)

Lexatumumab (HGS-ETR2)

Lexatumumab $0.1,0.3,1.0,3.0$, 10.0, $20.0 \mathrm{mg} / \mathrm{kg}$ q3w (phase la; interim data)

Lexatumumab 0.1, 0.3, 1.0, 3.0, $10.0 \mathrm{mg} / \mathrm{kg}$ q2w (phase la)

Lexatumumab 5.0, $10.0 \mathrm{mg} / \mathrm{kg}+$ gemcitabine-FOLFIRI q2w or pemetrexed-doxorubicin q3w (phase lb; interim data)

\section{Apomab}

Apomab 1.0, 4.0, 10.0, 15.0, 20.0

$\mathrm{mg} / \mathrm{kg}$ q4w cycle $1, \mathrm{q} 2 \mathrm{w}$, cycles

1-8 (phase la; interim data)

\section{AMG-655}

AMG-655, 0.3, 1.0, 3.0, 10.0,

$20.0 \mathrm{mg} / \mathrm{kg}$ q2w (phase la; interim data)

\section{No. of patients (evaluable); disease characteristics}

51 (32); advanced solid tumors or NHL

10 (8 response); low-grade NHL that has relapsed after previous rituximabcontaining therapy

49; advanced solid tumors

19 (39\%) SDs, with 2

(4\%) SDs lasting $9 \mathrm{mo}$

24 (24); advanced solid tumors

28 (26); advanced solid tumors

32 (32); advanced solid tumors

40 (40); relapsed or refractory NHL

38 (35); relapsed or refractory stage IIIB/IV or recurrent CRC

32 (32); relapsed or refractory stage IIIB/IV or recurrent NSCLC

37 (37); advanced

solid tumors

31 (31); advanced solid tumors and lymphoma 41 ; range of cancer types

50 (37 safety; 23 response); advanced treatment-refractory solid tumors

22 (21); advanced solid tumors

\section{Activity \\ (evaluable patients)}

1 (3\%) PR

(chondrosarcoma);

$17(53 \%)$ SDs

2 (20\%) CR; 1 (10\%)

PR; $5(50 \%)$ SDs

$8(33 \%)$ SDs

$6(23 \%)$ PRs cancer); 13 (50\%) SDs cancer, 2 biliary tract 1 unknown); 14 (44\%) SDs

1 (3\%) CR (follicular (follicular lymphoma); $12(30 \%)$ SDs

$12(34 \%)$ SDs

$9(29 \%)$ SDs

$11(30 \%)$ SDs

$10(32 \%)$ SDs

PRs reported (data not disclosed)

1 (5\%) PR (NSCLC);
(4 adenocarcinoma,

1 lung cancer, 1 peritoneal

$9(28 \%)$ PRs (3 pancreatic cancer, 1 head and neck cancer, 2 adenocarcinoma, lymphoma); 2 (5\%) PRs

$2(9 \%) \mathrm{MRs} ; 12$ (52\%) SDs $10(48 \%)$ SDs, including 1 metabolic PR (CRC)
1 DLT (asymptomatic reversible transaminitis) at $10 \mathrm{mg} / \mathrm{kg}$ possibly related to Apomab; no antidrug antibodies detected

No drug-related DLT; no antidrug antibodies detected

2 SAEs (bilateral pneumonia and septic shock, ileus) possibly related to rhApo2L/TRAIL

102

4 DLTs: septic cholangitis unrelated to syndrome, $2 \mathrm{gr} 3$ elevations of liver function tests (bilirubin, transaminitis) probably related to mapatumumab; no antidrug antibodies

2 DLTs: gr 3 thrombocytopenia, gr 3 hypertension possibly/probably related to mapatumumab; no antidrug antibodies 2 DLTs (gr 3 neutropenia, gr 3 HGS-ETR1 hypersensitivity) possibly/probably related to mapatumumab; $1 \mathrm{gr} 3$ to mapatumumab

8 DLTs: 1 gr 4 fatigue, 1 gr 4 thrombocytopenia, 1 neutropenic fever, $1 \mathrm{gr} 3$ elevated ALT + GGT (due to bile construction) possibly/probably related to mapatumumab; 1 gr 3 hypokalemia related to cisplatin; 4 gr 3 elevated ALT, 1 gr 3 elevated AST related to gemcitabine 2 SAEs (shingles, fever) possibly/ probably related to mapatumumab

1 SAE (vomiting) possibly/probably related to mapatumumab

No drug-related DLT

$20 \mathrm{mg} / \mathrm{kg}$ as DLT dose; 2 DLTs at 20.0 $\mathrm{mg} / \mathrm{kg}$ (gr 3 hyperamylasemia; gr 4 rena failure, elevated AST, ALT, and bilirubin); 1 DLT (gr 3 hyperamylasemia) at $1.0 \mathrm{mg} / \mathrm{kg}$ possibly/probably related to lexatumumab; no antidrug antibodies detected

1 DLT (gr 3 hyperamylasemia) at $10 \mathrm{mg} / \mathrm{kg}$ possibly/probably related to lexatumumab 3 SAEs (anemia, fatigue, dehydration) possibly related to lexatumumab

\section{Ref.}

101

104

antibodies detected treatment, acute respiratory distress paclitaxel sensitivity DLT not attributed 
reached $(103,104)$. In the study of Tolcher and colleagues (103), 2 patients administered $10 \mathrm{mg} / \mathrm{kg}$ every 2 weeks had elevated liver function tests, probably related to mapatumumab. Stable disease (SD) has been the best clinical response for mapatumumab in the phase Ia setting $(103,104)$. In contrast, phase Ib studies of the agent in combination with either paclitaxel-cisplatin or gemcitabine-cisplatin have yielded partial responses (PRs) in several patients $(23 \%$ and $28 \%$, respectively) $(105,106)$. This has been associated with an increase in adverse events, with neutropenia, fatigue, and thrombocytopenia being the major toxicities reported; there also have been several instances of grade 3 elevated liver enzymes. A mapatumumab single-agent phase II study in NHL has yielded 3 (8\%) objective responses (107). However, phase II single-agent studies in CRC and NSCLC have produced SD as the best response (34\% and $29 \%$, respectively) $(108,109)$. Mapatumumab monotherapy was well tolerated in the phase II setting, with a single drug-related serious adverse event (SAE) (vomiting) reported.

In results similar to those for mapatumumab, several patients have experienced SD with single-agent lexatumumab in a phase Ia study, although no tumor response has been observed to date (110, 111). In contrast, tumor shrinkage has been observed in a phase Ib study of lexatumumab plus gemcitabine-FOLFIRI or pemetrexeddoxorubicin, with 3 of the 41 patients who took part achieving a PR (112). Several grade 3 toxicities - including elevated liver enzymes - were attributed to lexatumumab in the phase Ia study; the MTD was defined as $20 \mathrm{mg} / \mathrm{kg}$ (110). SAE data have yet to be published for the combination trial.

Preliminary phase Ia data are available also for DR5-targeting Apomab and AMG-655. Apomab was reported to be safe and well tolerated and yielded $2(9 \%)$ minor responses (in patients with CRC and granulosa cell ovarian cancer) and 52\% SDs (113). A single dose-limiting toxicity (DLT) comprising reversible transaminitis occurred with Apomab $(10 \mathrm{mg} / \mathrm{kg})$; an MTD has yet to be reached. AMG-655 achieved 1 (5\%) PR (in a patient with NSCLC), and 10 (48\%) SDs; a metabolic PR was recorded in a patient with CRC and SD (114). AMG-655 was well tolerated: no DLTs were reported and an MTD has yet to be determined.

rhApo2L/TRAIL has been well tolerated in the phase Ia setting, yielding SD in the majority (53\%) of patients and a single (3\%) PR in a patient with chondrosarcoma (101). The trial is ongoing, with an MTD yet to be reached. Interim results from a phase Ib study of rhApo2L/TRAIL plus rituximab in patients with low-grade NHL who had previously failed rituximab-containing therapy showed the combination to be well tolerated and active, with 2 (25\%) complete responses, 1 (13\%) PR, and 5 (63\%) SDs achieved (102). Two SAEs possibly related to rhApo2L/TRAIL included pneumonia together with septic shock and ileus (the patient continued on study); an MTD of rhApo2L/TRAIL in combination with rituximab has yet to be defined.

Finally, early data from a phase Ia study of Ad5-TRAIL gene therapy for organ-confined prostate cancer showed the treatment was well tolerated in 3 patients administered the initial dose level via intraprostatic injection (115).

The current phase Ia clinical trial data indicate that SD is the best clinical outcome for the majority of patients, with some cases of objective response. These results are encouraging, especially considering that phase I trials are designed primarily to evaluate safety and pharmacokinetics and that patients participating in such trials often have advanced malignant disease that has not been responsive to various other therapies. Moreover, the data with PARAs to date suggest that the most preferred clinical strategy for this novel class of therapies is in combination with other treatment modalities, including nonspecific interventions such as chemotherapy as well as more targeted agents.

These observations support further investigation of the PARAs in combination with other targeted therapies that have recently redefined the standard of care. The study of PARAs combined with VEGF or VEGFR-targeting antiangiogenic agents, EGFR inhibitors, proteasome inhibitors, or anti-CD20 antibodies - among other approaches - is warranted. Furthermore, it will be interesting to conduct combination trials of PARAs with other proapoptotic therapies focused on Bcl-2 proteins and IAPs.

The first randomized phase II trials of PARAs in combination with other targeted therapy have begun. Mapatumumab plus bortezomib is being studied for the second-line treatment of multiple myeloma, while both rhApo2L/TRAIL and Apomab are being tested in combination with rituximab for the treatment of relapsed follicular NHL. Finally, Apomab plus bevacizumab is being evaluated for the first-line treatment of NSCLC.

The low toxicity of the PARAs further argues for their ongoing investigation in combination with current established therapies. However, as the effects of the PARAs in humans continue to be defined, appropriate caution is required when these agents are combined with drugs that may be associated with side effects on normal tissues.

\section{The intrinsic pathway: Bcl-2 family proteins as therapeutic targets}

To date, strategies targeting the intrinsic apoptosis pathway have focused on Bcl-2 family proteins (11). Bcl-2 was originally validated as an attractive anticancer target in studies that showed its ability to cooperate with the myc oncogene or with mutant p53 in driving B cell lymphomas in mice $(32,116)$. This was further supported by a mouse model of leukemia, in which Bcl-2 elimination resulted in rapid loss of leukemic cells and significantly prolonged survival (117). The most clinically advanced anti-Bcl-2 therapy, the antisense agent oblimersen, has reached phase III development. Results have been encouraging in patients with chronic lymphocytic leukemia, with improved response and remission rates and prolonged progression-free survival (118). Positive results also have been observed among patients with advanced, relapsed melanoma, with evidence of prolonged overall survival (119). However, results in other tumor types, including prostate, myeloma, and acute myeloid leukemia, have been disappointing, perhaps attributable in part to the reliance of this molecule on antisense mechanisms to attenuate $\mathrm{Bcl}-2$ expression. In this regard, $\mathrm{Bcl}-2$ downregulation has not been consistently demonstrated preclinically (120), and off-target effects have limited the dose level (121). It is important not to discount the Bcl-2 target based solely on oblimersen's performance.

Several promising small molecule antagonists of Bcl-2 are in early development. The R-(-)-gossypol derivative AT-101, a BH3 mimetic, is in phase I testing, as is ABT-263, a small molecule that binds with subnanomolar affinity to $\mathrm{Bcl}-2, \mathrm{Bcl}-\mathrm{X}_{\mathrm{L}}$, and Bcl-W. Both molecules have demonstrated single-agent activity and an additive effect in combination with cytotoxic agents in preclinical studies $(122,123)$. GX-15-070 (obatoclax), which is reported to inhibit all 5 members of the Bcl-2 family, is in phase II clinical trials (124). Mcl-1 antagonists are in preclinical development. 


\section{science in medicine}

\section{Targeting intracellular caspase inhibitors}

Other strategies involve modulation of cellular caspase inhibitors, such as the IAPs and c-FLIP. Overexpression of IAPs is implicated in the resistance of some cancers to apoptosis; for example, ML-IAP, which is preferentially expressed in human melanomas, inhibits apoptosis induced via the proapoptotic receptors or by chemotherapy (125). One promising anticancer approach involves the application of small molecules that bind IAPs and prevent their inhibitory interaction with caspases. For instance, polyphenylurea XIAP inhibitors have been shown in vitro to overcome the inhibitory effects of XIAP on effector caspases 3 and 7, inducing apoptosis in a range of solid tumor and leukemia cells with little toxicity to normal cells (126). These molecules also sensitized tumor cells to apoptosis induced by chemotherapy or by Apo2L/TRAIL. Another approach involves small molecule drugs that mimic the activity of Smac by binding to IAPs and blocking their activity. Notably, Smac mimetics can synergize with Apo2L/TRAIL to induce high levels of caspase activation and apoptosis in human cancer cells (89-91). There are also two antisense-based inhibitors of IAPs in phase I/II clinical development following positive results in preclinical human xenograft models: ISIS 23722 (LY2181308), which inhibits the IAP family member survivin, and AEG-35156 (GEM640 ), which is under investigation for pancreatic cancer, breast cancer, and NSCLC (127).

A number of compounds that modulate c-FLIP have been described. Natural and synthetic ligands of the PPAR $\gamma$ were shown to reduce levels of c-FLIP selectively by inducing ubiquitination and proteasome-dependent degradation (128). Furthermore, these agents sensitized epithelial tumor cell lines to apoptosis induction by Apo2L/TRAIL (128). More recently, Schimmer et al. described two compounds, 5809354 and 5569100, which reduced the expression of c-FLIP and sensitized PPC-1 cells to Apo2L/ TRAIL-induced apoptosis (129).

\section{Future clinical trial design}

The shift away from screening-based discovery of cytotoxic compounds to molecularly targeted therapies such as the PARAs makes trial design more challenging. Some of the newer treatments may cause visible tumor reduction and may be assessable by traditional means; however, many may not.

Indications are that the PARAs are unlikely to cause meaningful toxicity and therefore phase I trial design preferably moves beyond dose selection based on toxicity to the more relevant endpoint of the dose required to maximally inhibit the specific target: the optimal biologic dose. There is a need also to define biomarkers of antitumor activity for all stages of development of targeted therapy. Although PARAs are highly specific for proapoptotic receptors, experimental data suggest that the degree of receptor expression may not relate to antitumor activity $(17,62)$. Other biologic determinants of sensitivity to apoptosis stimulation via the extrinsic and intrinsic pathways - such as specific O-glycosylation enzyme levels, $p 53$ status, myc amplification, or relative Bcl-2 family protein expression - may need to be explored.

The ultimate goal is the identification of the best biomarkers to aid the selection of patients most likely to benefit from PARA therapy and its combination with other treatments, their validation, and eventual integration into clinical practice.

\section{Conclusion}

Research efforts over the past decade have significantly added to our knowledge of the multiple mechanisms and factors that control oncogenesis, regulate apoptosis, and contribute to treatment resistance of cancer cells. This new understanding has facilitated the rational design of molecularly targeted proapoptotic anticancer therapies. One particularly intriguing approach is directed toward the extrinsic apoptosis pathway using PARAs (a therapeutic class including rhApo2L/TRAIL and several agonistic mAbs). Indeed, PARAs are among the most advanced of the proapoptotic approaches in development, and it is anticipated that some of these agents may become clinically available during the next decade. The PARAs' mechanism of action underpins their potential: they stimulate apoptosis via the extrinsic pathway, which is independent of p53 and distinct from the indirect targeting of the intrinsic pathway by conventional therapy. Therefore, PARAs may promote apoptosis in susceptible cancer cells with a wide spectrum of responsiveness to current therapy. Indeed, rhApo2L/TRAIL has demonstrated a synergistic effect in combination with several conventional and targeted therapies in numerous tumor types in multiple preclinical models and has been shown to be capable of overcoming chemoresistance. Of particular interest is the observation that PARAs selectively induce apoptosis in tumor cells but not normal cells. This relative selectivity has been illustrated consistently in the preclinical setting and appears to be verified by the early clinical data, pointing to the potential for a relatively safe and well-tolerated class of anticancer agents. This important milestone sets a strong foundation for evaluating PARAs in combination with various other therapeutic strategies, ranging from conventional chemotherapies, through approaches designed to inhibit tumor growth signaling and angiogenesis, to agents that target other aspects of the apoptosis pathways.

\section{Acknowledgments}

Support for third-party editorial assistance for this manuscript was provided by Genentech.

Address correspondence to: Roy S. Herbst, Department of Thoracic/ Head and Neck Medical Oncology, Department of Cancer Biology, University of Texas MD Anderson Cancer Center, 1515 Holcombe Blvd., Unit 432, Houston, Texas 77030, USA. Phone: (713) 7926363; Fax: (713) 792-1220; E-mail: rherbst@mdanderson.org. Or to: Avi Ashkenazi, Department of Molecular Oncology, Genentech Inc., 1 DNA Way, South San Francisco, California 94080, USA. Phone: (650) 225-1853; Fax: (650) 467-8195; E-mail: aa@gene.com.
1. Ghobrial, I.M., Witzig, T.E., and Adjei, A.A. 2005 Targeting apoptosis pathways in cancer therapy. CA Cancer J. Clin. 55:178-194.

2. Broker, L.E., Kruyt, F.A., and Giaccone, G. 2005. Cell death independent of caspases: a review. Clin. Cancer Res. 11:3155-3162.

3. Gulbins, E., Jekle, A., Ferlinz, K., Grassmé, H., and Lang, F. 2000. Physiology of apoptosis. Am. J. Physiol. Renal Physiol. 279:F605-F615.

4. Lavrik, I.N., Golks, A., and Krammer, P.H. 2005.
Caspases: pharmacological manipulation of cell death. J. Clin. Invest. 115:2665-2672.

5. Thornberry, N.A., and Lazebnik, Y. 1998. Caspases: enemies within. Science. 281:1312-1316.

6. Zimmermann, K.C., Bonzon, C., and Green, D.R. 2001. The machinery of programmed cell death. Pharmacol. Ther. 92:57-70.

7. Tschopp, J., Irmler, M., and Thome, M. 1998. Inhibition of fas death signals by FLIPs. Curr. Opin. Immunol. 10:552-558.
8. Grundhoff, A., and Ganem, D. 2001. Mechanisms governing expression of the v-FLIP gene of Kaposi's sarcoma-associated herpesvirus. J. Virol. 75:1857-1863.

9. Fulda, S., and Debatin, K.M. 2006. Extrinsic versus intrinsic apoptosis pathways in anticancer chemotherapy. Oncogene. 25:4798-4811.

10. Coultas, L., and Strasser, A. 2003. The role of the $\mathrm{Bcl}-2$ protein family in cancer. Semin. Cancer Biol. 13:115-123. 
11. Letai, A. 2005. Pharmacological manipulation of Bcl-2 family members to control cell death. J. Clin. Invest. 115:2648-2655.

12. Henry-Mowatt, J., Dive, C., Martinou, J.C., and James, D. 2004. Role of mitochondrial membrane permeabilization in apoptosis and cancer. Oncogene. 23:2850-2860

13. Reed, J.C. 2006. Drug insight: cancer therapy strategies based on restoration of endogenous cell death mechanisms. Nat. Clin. Pract. Oncol. 3:388-398.

14. Willis, S.N., et al. 2007. Apoptosis initiated when $\mathrm{BH} 3$ ligands engage multiple $\mathrm{Bcl}-2$ homologs, not Bax or Bak. Science. 315:856-859s

15. Vousden, K.H., and Lu, X. 2002. Live or let die: the cell's response to p53. Nat. Rev. Cancer. 2:594-604.

16. Wu, Y., Mehew, J.A., Heckman, C.A., Arcinas, M., and Boxer, L.M. 2001. Negative regulation of bcl-2 expression by $\mathrm{p} 53$ in hematopoietic cells. Oncogene. 20:240-251.

17. Ashkenazi, A. 2002. Targeting death and decoy receptors of the tumour-necrosis factor superfamily. Nat. Rev. Cancer. 2:420-430.

18. Debatin, K.M., and Krammer, P.H. 2004. Death receptors in chemotherapy and cancer. Oncogene. 23:2950-2966.

19. Scaffidi, C., et al. 1998. Two CD95 (APO-1/Fas) signaling pathways. EMBOJ. 17:1675-1687.

20. Ozoren, N., and El-Deiry, W.S. 2002. Defining characteristics of Types I and II apoptotic cells in response to TRAIL. Neoplasia. 4:551-557.

21. Luo, X., et al. 1998. Bid, a Bcl2 interacting protein, mediates cytochrome $\mathrm{c}$ release from mitochondria in response to activation of cell surface death receptors. Cell. 94:481-490.

22. Li, H., et al. 1998. Cleavage of BID by caspase 8 mediates the mitochondrial damage in the Fas pathway of apoptosis. Cell. 94:491-501.

23. LeBlanc, H., et al. 2002. Tumor-cell resistance to death receptor-induced apoptosis through mutational inactivation of the proapoptotic $\mathrm{Bcl}-2$ homolog Bax. Nat. Med. 8:274-281.

24. Fadeel, B., and Orrenius, S. 2005. Apoptosis: a basic biological phenomenon with wide-ranging implications in human disease. J. Intern. Med. 258:479-517.

25. Smyth, M.J., et al. 2002. New aspects of naturalkiller-cell surveillance and therapy of cancer. Nat. Rev. Cancer. 2:850-861.

26. Janssen, E.M., et al. 2005. CD4+ T-cell help controls CD8+ T-cell memory via TRAIL-mediated activation-induced cell death. Nature. 434:88-93.

27. LeBlanc, H.N., and Ashkenazi, A. 2003. Apo2L/ TRAIL and its death and decoy receptors. Cell Death Differ. 10:66-75.

28. Gong, B., and Almasan, A. 2000. Genomic organization and transcriptional regulation of human Apo2/TRAIL gene. Biochem. Biophys. Res. Commun. 278:747-752.

29. Sato, K., et al. 2001. Antiviral response by natural killer cells through TRAIL gene induction by IFNalpha/beta. Eur. J. Immunol. 31:3138-3146.

30. Sedger, L.M., et al. 1999. IFN-gamma mediates a novel antiviral activity through dynamic modulation of TRAIL and TRAIL receptor expression. J. Immunol. 163:920-926.

31. Hanahan, D., and Weinberg, R.A. 2000. The hallmarks of cancer. Cell. 100:57-70.

32. Lowe, S.W., Cepero, E., and Evan, G. 2004. Intrinsic tumour suppression. Nature. 432:307-315.

33. Kaufmann, S.H., and Vaux, D.L. 2003. Alterations in the apoptotic machinery and their potential role in anticancer drug resistance. Oncogene. 22:7414-7430.

34. Mollinedo, F., and Gajate, C. 2003. Microtubules, microtubule-interfering agents and apoptosis Apoptosis. 8:413-450.

35. Pommier, Y., Sordet, O., Antony, S., Hayward, R.L., and Kohn, K.W. 2004. Apoptosis defects and chemotherapy resistance: molecular interaction maps and networks. Oncogene. 23:2934-2949.
36. Igney, F.H., and Krammer, P.H. 2002. Death and anti-death: tumour resistance to apoptosis. Nat. Rev. Cancer. 2:277-288.

37. Hollstein, M., et al. 1994. Database of p53 gene somatic mutations in human tumors and cell lines. Nucleic Acids Res. 22:3551-3555.

38. Lee, J.M., and Bernstein, A. 1995. Apoptosis, cancer and the p53 tumor suppressor gene. Cancer Metastasis Rev. 14:149-161.

39. Fesik, S.W. 2005. Promoting apoptosis as a strategy for cancer drug discovery. Nat. Rev. Cancer. 5:876-885.

40. Fischer, U., and Schulze-Osthoff, K. 2005. Apoptosis-based therapies and drug targets. Cell Death Differ. 12(Suppl. 1):942-961.

41. Fischer, U., and Schulze-Osthoff, K. 2005. New approaches and therapeutics targeting apoptosis in disease. Pharmacol. Rev. 57:187-215.

42. Grunhagen, D.J., et al. 2006. Technology insight: utility of TNF-alpha-based isolated limb perfusion to avoid amputation of irresectable tumors of the extremities. Nat. Clin. Pract. Oncol. 3:94-103.

43. Nagata, S. 1997. Apoptosis by death factor. Cell. 88:355-365.

44. Ashkenazi, A., et al. 1999. Safety and antitumor activity of recombinant soluble Apo2 ligand. J. Clin. Invest. 104:155-162.

45. Chuntharapai, A., et al. 2001. Isotype-dependent inhibition of tumor growth in vivo by monoclonal antibodies to death receptor 4. J. Immunol. 166:4891-4898.

46. Ichikawa, K., et al. 2001. Tumoricidal activity of a novel anti-human DR5 monoclonal antibody without hepatocyte cytotoxicity. Nat. Med. 7:954-960.

47. Lawrence, D., et al. 2001. Differential hepatocyte toxicity of recombinant Apo2L/TRAIL versions. Nat. Med. 7:383-385.

48. Sayers, T.J., and Murphy, W.J. 2006. Combining proteasome inhibition with TNF-related apoptosis-inducing ligand (Apo2L/TRAIL) for cancer therapy. Cancer Immunol. Immunother. 55:76-84.

49. Mitsiades, N., Poulaki, V., Tseleni-Balafouta, S., Koutras, D.A., and Stamenkovic, I. 2000. Thyroid carcinoma cells are resistant to FAS-mediated apoptosis but sensitive to tumor necrosis factorrelated apoptosis-inducing ligand. Cancer Res. 60:4122-4129.

50. Petak, I., Douglas, L., Tillman, D.M., Vernes, R., and Houghton, J.A. 2000. Pediatric rhabdomyosarcoma cell lines are resistant to Fas-induced apoptosis and highly sensitive to TRAIL-induced apoptosis. Clin. Cancer Res. 6:4119-4127.

51. Thomas, W.D., and Hersey, P. 1998. TNF-related apoptosis-inducing ligand (TRAIL) induces apoptosis in Fas ligand-resistant melanoma cells and mediates CD4 T cell killing of target cells. J. Immunol. 161:2195-2200.

52. Marini, P., et al. 2005. Irradiation specifically sensitises solid tumour cell lines to TRAIL mediated apoptosis. BMC Cancer. 5:5.

53. Mühlethaler-Mottet, A., Bourloud, K.B., Auderset, K., Joseph, J.M., and Gross, N. 2004. Drug-mediated sensitization to TRAIL-induced apoptosis in caspase-8-complemented neuroblastoma cells proceeds via activation of intrinsic and extrinsic pathways and caspase-dependent cleavage of XIAP, $\mathrm{Bcl}-\mathrm{x}_{\mathrm{L}}$ and RIP. Oncogene. 23:5415-5425.

54. Jin, H., et al. 2004. Apo2 ligand/tumor necrosis factor-related apoptosis-inducing ligand cooperates with chemotherapy to inhibit orthotopic lung tumor growth and improve survival. Cancer Res. 64:4900-4905.

55. Gliniak, B., and Le, T. 1999. Tumor necrosis factor-related apoptosis-inducing ligand's antitumor activity in vivo is enhanced by the chemotherapeutic agent CPT-11. Cancer Res. 59:6153-6158.

56. Walczak, H., et al. 1999. Tumoricidal activity of tumor necrosis factor-related apoptosis-inducing ligand in vivo. Nat. Med. 5:157-163.

57. Shankar, S., et al. 2004. The sequential treatment with ionizing radiation followed by TRAIL/Apo2L reduces tumor growth and induces apoptosis of breast tumor xenografts in nude mice. Int. J. Oncol. 24:1133-1140

58. Shankar, S., Singh, T.R., and Srivasta, R.K. 2004. Ionizing radiation enhances the therapeutic potential of TRAIL in prostate cancer in vitro and in vivo: intracellular mechanisms. Prostate. 61:35-49.

59. Wu, G.S., et al. 1997. KILLER/DR5 is a DNA damage-inducible p53-regulated death receptor gene. Nat. Genet. 17:141-143.

60. Mitsiades, C.S., et al. 2001. TRAIL/Apo2L ligand selectively induces apoptosis and overcomes drug resistance in multiple myeloma: therapeutic applications. Blood. 98:795-804.

61. Ravi, R., et al. 2004. Elimination of hepatic metastases of colon cancer cells via p53-independent cross-talk between irinotecan and Apo2 ligand/ TRAIL. Cancer Res. 64:9105-9114.

62. Kelley, R.F., et al. 2004. Receptor-selective mutants of Apo2L/TRAIL reveal a greater contribution of DR5 than DR4 to apoptosis signaling. J. Biol. Chem. 280:2205-2212.

63. Zhang, L., and Fang, B. 2005. Mechanisms of resistance to TRAIL-induced apoptosis in cancer. Cancer Gene Ther. 12:228-237.

64. Jin, Z., McDonald, E.R., 3rd, Dicker, D.T., and El-Deiry, W.S. 2004. Deficient tumor necrosis factor-related apoptosis-inducing ligand (TRAIL) death receptor transport to the cell surface in human colon cancer cells selected for resistance to TRAIL-induced apoptosis. J. Biol. Chem. 279:35829-35839.

65. Sinicrope, F.A., Penington, R.C., and Tang, X.M. 2004. Tumor necrosis factor-related apoptosisinducing ligand-induced apoptosis is inhibited by $\mathrm{Bcl}-2$ but restored by the small molecule $\mathrm{Bcl}-2$ inhibitor, HA 14-1, in human colon cancer cells. Clin. Cancer Res. 10:8284-8292.

66. Kandasamy, K., et al. 2003. Involvement of proapoptotic molecules Bax and Bak in tumor necrosis factor-related apoptosis-inducing ligand (TRAIL)induced mitochondrial disruption and apoptosis: differential regulation of cytochrome $\mathrm{c}$ and Smac/ DIABLO release. Cancer Res. 63:1712-1721.

67. Sharp, D.A., Lawrence, D.A., and Ashkenazi, A. 2005. Selective knockdown of the long variant of cellular FLICE inhibitory protein augments death receptor-mediated caspase- 8 activation and apoptosis. J. Biol. Chem. 280:19401-19409.

68. Wagner, K.W., et al. 2007. Death-receptor O-glycosylation controls tumor-cell sensitivity to the proapoptotic ligand Apo2L/TRAIL. Nat. Med. 13:1070-1077.

69. Ricci, M.S., et al. 2004. Direct repression of FLIP expression by c-myc is a major determinant of TRAIL sensitivity. Mol. Cell. Biol. 24:8541-8555.

70. Ricci, M.S., et al. 2007. Reduction of TRAILinduced Mcl-1 and cIAP2 by c-Myc or sorafenib sensitizes resistant human cancer cells to TRAILinduced death. Cancer Cell. 12:66-80.

71. Meng, X., et al. 2007. Mcl-1 as a buffer for proapoptotic Bcl-2 family members during TRAIL-induced apoptosis: a mechanistic basis for sorafenib (BAY 43-9006)-induced TRAIL sensitization. J. Biol. Chem. 282:29831-29846.

72. Rosato, R.R., et al. 2007. The multikinase inhibitor sorafenib potentiates TRAIL lethality in human leukemia cells in association with Mcl-1 and cFLIPL down-regulation. Cancer Res. 67:9490-9500.

73. Lacour, S., et al. 2001. Anticancer agents sensitize tumor cells to tumor necrosis factor-related apoptosis-inducing ligand-mediated caspase- 8 activation and apoptosis. Cancer Res. 61:1645-1651.

74. Naka, T., et al. 2002. Effects of tumor necrosis factor-related apoptosis-inducing ligand alone and in combination with chemotherapeutic agents on patients' colon tumors grown in SCID mice. Cancer 
Res. 62:5800-5806.

75. Xiang, H., et al. 2002. Enhanced tumor killing by Apo2L/TRAIL and CPT-11 co-treatment is associated with p 21 cleavage and differential regulation of Apo2L/TRAIL ligand and its receptors. Oncogene. 21:3611-3619.

76. El-Zawahry, A., McKillop, J., and Voelkel-Johnson, C. 2005. Doxorubicin increases the effectiveness of Apo2L/TRAIL for tumor growth inhibition of prostate cancer xenografts. BMC Cancer. 5:2.

77. Nimmanapalli, R., et al. 2001. Pretreatment with paclitaxel enhances apo-2 ligand/tumor necrosis factor-related apoptosis-inducing ligand-induced apoptosis of prostate cancer cell by inducing death receptors 4 and 5 protein levels. Cancer Res. 61:759-763.

78. Ray, S., and Almasan, A. 2003. Apoptosis induction in prostate cancer cells and xenografts by combined treatment with Apo2 ligand/tumor necrosis factor-related apoptosis-inducing ligand and CPT-11. Cancer Res. 63:4713-4723.

79. Hylander, B.L., et al. 2005. The anti-tumor effect of Apo2L/TRAIL on patient pancreatic adenocarcinomas grown as xenografts in SCID mice. J. Transl. Med. 3:22.

80. Mizutani, Y., Yoshida, O., Miki, T., and Bonavida, B. 1999. Synergistic cytotoxicity and apoptosis by Apo-2 ligand and adriamycin against bladder cancer cells. Clin. Cancer Res. 5:2605-2612.

81. Vignati, S., Codegoni, A., Polato, F., and Broggini, M. 2002. Trail activity in human ovarian cancer cells: potentiation of the action of cytotoxic drugs. Eur. J. Cancer. 38:177-183.

82. Cuello, M., Ettenberg, S.A., Nau, M.M., and Lipkowitz, S. 2001. Synergistic combination of apoptosis by the combination of trail and chemotherapy in chemoresistant ovarian cancer cells. Gynecol. Oncol. 81:380-390.

83. Frese, S., Brunner, T., Gugger, M., Uduehi, A., and Schmid, R.A. 2002. Enhancement of Apo2L/TRAIL (tumor necrosis factor-related apoptosis-inducing ligand)-induced apoptosis in non-small cell lung cancer cell lines by chemotherapeutic agents without correlation to the expression level of cellular protease caspase- 8 inhibitory protein. J. Thorac. Cardiovasc. Surg. 123:168-174.

84. Odoux, C., and Albers, A. 2004. Additive effects of TRAIL and paclitaxel on cancer cells: implications for advances in cancer therapy. Vitam. Horm. 67:385-407.

85. Brooks, A.D., et al. 2005. The proteasome inhibitor bortezomib (Velcade) sensitizes some human tumor cells to Apo2L/TRAIL-mediated apoptosis. Ann. N. Y. Acad. Sci. 1059:160-167.

86. Johnson, T.R., et al. 2003. The proteasome inhibitor PS-341 overcomes TRAIL resistance in Bax and caspase 9-negative or Bcl-xL overexpressing cells. Oncogene. 22:4953-4963.

87. Zhu, H., et al. 2005. Proteasome inhibitor-mediated TRAIL resensitization and Bik accumulation. Cancer Biol. Ther. 4:781-786.

88. Ray, S., Bucur, O., and Almasan, A. 2005. Sensitization of prostate carcinoma cells to Apo2L/TRAIL by a Bcl-2 family protein inhibitor. Apoptosis. 10:1411-1418.

89. Guo, F., et al. 2002. Ectopic overexpression of second mitochondria-derived activator of caspases (Smac/DIABLO) or cotreatment with $\mathrm{N}$-terminus of Smac/DIABLO peptide potentiates epothilone $B$ derivative-(BMS 247550) and Apo-2L/TRAILinduced apoptosis. Blood. 99:3419-3426.

90. Li, L., et al. 2004. A small molecule Smac mimic potentiates TRAIL- and TNF $\alpha$-mediated cell death. Science. 305:1471-1474.

91. Fulda, S., et al. 2002. Smac agonists sensitize for Apo2L/TRAIL- or anticancer drug-induced apoptosis and induce regression of malignant glioma in vivo. Nat. Med. 8:808-815.
92. Nakata, S., et al. 2004. Histone deacetylase inhibitors upregulate death receptor 5/TRAIL-R2 and sensitize apoptosis induced by TRAIL/APO2-L in human malignant tumor cells. Oncogene. 23:6261-6271.

93. Daniel, D., et al. 2007. Cooperation of the pro-apoptotic receptor agonist rhApo2L/TRAIL with the CD20 antibody rituximab against non-Hodgkin's lymphoma xenografts. Blood. 110:4037-4046.

94. Hyer, M.L., et al. 2005. Synthetic triterpenoids cooperate with tumor necrosis factor-related apoptosis-inducing ligand to induce apoptosis of breast cancer cells. Cancer Res. 65:4799-4808.

95. Nikrad, M., et al. 2005. The proteasome inhibitor bortezomib sensitizes cells to killing by death receptor ligand TRAIL via BH3-only proteins Bik and Bim. Mol. Cancer Ther. 4:443-449.

96. Corazza, N., et al. 2006. TRAIL receptor-mediated JNK activation and Bim phosphorylation critically regulate Fas-mediated liver damage and lethality. J. Clin. Invest. 116:2493-2499.

97. Hao, C., et al. 2004. TRAIL inhibits tumor growth but is nontoxic to human hepatocytes in chimeric mice. Cancer Res. 64:8502-8506.

98. Ganten, T.M., et al. 2006. Preclinical differentiation between apparently safe and potentially hepatotoxic applications of TRAIL either alone or in combination with chemotherapeutic drugs. Clin. Cancer Res. 12:2640-2646.

99. Rowinsky, E.K. 2005. Targeted induction of apoptosis in cancer management: the emerging role of tumor necrosis factor-related apoptosis-inducing ligand receptor activating agents. J. Clin. Oncol. 23:9394-9407.

100.Adams, C., et al. 2008. Structural and functional analysis of the interaction between the agonistic monoclonal antibody Apomab and the proapoptotic receptor DR5. Cell Death Differ. 15:751-756

101. Herbst, R.S., et al. 2006. A phase I safety and pharmacokinetic study of recombinant Apo2L/TRAIL, an apoptosis-inducing protein in patients with advanced cancer [abstract]. Proceedings of the American Society of Clinical Oncology. 24:3013.

102. Yee, L., et al. 2007. A Phase Ib safety and pharmacokinetic study of recombinant human Apo2L/TRAIL in combination with rituximab in patients with low-grade non-Hodgkin's lymphoma [abstract]. Proceedings of the American Society of Clinical Oncology. 25:8078.

103. Tolcher, A.W., et al. 2007. Phase I pharmacokinetic and biologic correlative study of mapatumumab, a fully human monoclonal antibody with agonist activity to tumor necrosis factor-related apoptosis-inducing ligand receptor-1. J. Clin. Oncol. 25:1390-1395.

104. Hotte, S.J., et al. 2005. HGS-ETR1, a fully human monoclonal antibody to the tumor necrosis factorrelated apoptosis-inducing ligand death receptor 1 (TRAIL-R1) in patients with advanced solid cancer: results of a phase 1 trial [abstract]. Proceedings of the American Society of Clinical Oncology. 23:3052.

105. Chow, L.Q., et al. 2006. HGS-ETR1, an antibody targeting TRAIL-R1, in combination with paclitaxel and carboplatin in patients with advanced solid malignancies: results of a phase 1 and PK study [abstract]. Proceedings of the American Society of Clinical Oncology. 24:2525.

106.Mom, C.H., et al. 2006. Mapatumumab, a fully human agonistic monoclonal antibody that targets TRAIL-R1, in combination with gemcitabine and cisplatin: a Phase $1 \mathrm{~b}$ study in patients with advanced solid malignancies [abstract 202]. Presented at the AACR-NCI-EORTC International Conference on Molecular Targets and Cancer Therapies. November 7-10. Prague, Czech Republic.

107. Younes, A., et al. 2005. Results of a Phase 2 trial of HGS-ETR1 (agonistic human monoclonal antibody to TRAIL receptor 1 ) in subjects with relapsed/refractory non-Hodgkin's lymphoma (ETR1-HM01) [abstract]. Presented at the Ameri- can Society of Hematology Annual Meeting. December 10-13. Atlanta, Georgia, USA.

108.Kanzler, S., et al. 2005. Results of a Phase 2 trial of HGS-ETR1 (agonistic human monoclonal antibody to TRAIL receptor 1 ) in subjects with relapsed or refractory colorectal cancer (CRC) [abstract 630]. Presented at the 13th European Cancer Conference. October 30-November 3. Paris, France.

109. Bonomi, P., et al. 2005. Results of a Phase 2 trial of HGS-ETR1 (agonistic human monoclonal antibody to TRAIL receptor 1) in subjects with relapsed/ recurrent non-small cell lung cancer [abstract 1851]. Presented at the 11th World Conference on Lung Cancer. July 3-6. Barcelona, Spain.

110.Attard, G., et al. 2005. Phase I and pharmacokinetic study of HGS-ETR2, a human monoclonal antibody to TRAIL-R2, in patients with advanced solid malignancies [abstract B114]. Presented at the AACR-NCI-EORTC International Conference on Molecular Targets and Cancer Therapies. November 14-18. Philadelphia, Pennsylvania, USA.

111.Patnaik, A., et al. 2006. HGS-ETR2, a fully human monoclonal antibody to TRAIL-R2: results of a phase I trial in patients with advanced solid tumors [abstract]. Proceedings of the American Society of Clinical Oncology. 24:3012.

112.Sikic, B.I., et al. 2007. A phase Ib study to assess the safety of lexatumumab, a human monoclonal antibody that activates TRAIL-R2, in combination with gemcitabine, pemetrexed, doxorubicin or FOLFIRI [abstract]. Proceedings of the American Society of Clinical Oncology. 25:14006.

113. Camidge, D.R., et al. 2007. A phase I safety and pharmacokinetic study of Apomab, a human DR5 agonist antibody, in patients with advanced cancer [abstract]. Proceedings of the American Society of Clinical Oncology. 25:3582.

114.LoRusso, P., et al. 2007. First-in-human study of AMG 655, a pro-apoptotic TRAIL receptor-2 agonist, in adult patients with advanced solid tumors [abstract]. Proceedings of the American Society of Clinical Oncology. 25:3534.

115. Griffith, T.S., et al. 2005. Phase I study of Ad5TRAIL in men with clinically organ confined prostate cancer [abstract 4870]. Presented at the 2005 American Association for Cancer Research Annual Meeting. April 16-20. Anaheim, California, USA.

116.Strasser, A., Harris, A.W., Bath, M.L., and Cory, S. 1990. Novel primitive lymphoid tumours induced in transgenic mice by cooperation between myc and bcl-2. Nature. 348:331-333.

117.Letai, A., Sorcinelli, M.D., Beard, C., and Korsmeyer, S.J. 2004. Antiapoptotic Bcl-2 is required for maintenance of a model leukemia. Cancer Cell. 6:241-249.

118.O'Brien, S., et al. 2007. Randomized phase II trial of fludarabine plus cyclophosphamide with or without oblimersen sodium (Bcl-2 antisense) in patients with relapsed or refractory chronic lymphocytic leukemia. J. Clin. Oncol. 25:1114-1120.

119.Bedikian, A.Y., et al. 2006. Bcl-2 antisense (oblimersen sodium) plus dacarbazine in patients with advanced melanoma: the Oblimersen Melanoma Study. J. Clin. Oncol. 24:4738-4745.

120.Jahrsdorfer, B., et al. 2002. Modulation of malignant $\mathrm{B}$ cell activation and apoptosis by bcl-2 antisense ODN and immunostimulatory CPG ODN. J. Lenkoc. Biol. 72:83-92.

121. Waters, J.S., et al. 2000. Phase I clinical and pharmacokinetic study of Bcl-2 antisense oligonucleotide therapy in patients with non-Hodgkin's lymphoma. J. Clin. Oncol. 18:1812-1823.

122.Meng, X.W., Sun-Hee, L., and Kaufmann, S.H. 2006. Apoptosis in the treatment of cancer: a promise kept? Curr. Opin. Cell Biol. 18:668-676.

123. Oltersdorf, T., et al. 2005. An inhibitor of Bcl-2 family proteins induces regression of solid tumours. Nature. 435:677-681. 
124. Trudel, S., et al. 2007. Preclinical studies of the pan$\mathrm{Bcl}$ inhibitor obatoclax (GX015-070) in multiple myeloma. Blood. 109:5430-5438.

125.Vucic, D., Stennicke, H.R., Pisabarro, M.T., Salvesen, G.S., and Dixit, V.M. 2000. ML-IAP, a novel inhibitor of apoptosis that is preferentially expressed in human melanomas. Curr. Biol. 10:1359-1366.
126.Schimmer, A.D., et al. 2004. Small-molecule antagonists of apoptosis suppressor XIAP exhibit broad antitumor activity. Cancer Cell. 5:25-35.

127. LaCasse, E.C., et al. 2006. Preclinical characterization of AEG35156/GEM 640, a second-generation oligonucleotide targeting X-linked inhibitors of apoptosis. Clin. Cancer Res. 12:5231-5241.
128. Kim, Y., et al. 2002. An inducible pathway for degradation of FLIP proteins sensitizes tumor cells to TRAILinduced apoptosis. J. Biol. Chem. 277:22320-22329.

129.Schimmer, A.D., et al. 2006. Identification of small molecules that sensitize resistant tumor cells to tumor necrosis factor-family death receptors. Cancer Res. 66:2367-2375. 